\title{
Dynamic environments do not appear to constrain spider web building behaviour
}

\author{
Tom Mulder $^{1} \cdot$ Lucas Wilkins $^{1} \cdot$ Beth Mortimer ${ }^{1} \cdot$ Fritz Vollrath $^{1}[$
}

Received: 4 September 2020 / Revised: 4 January 2021 / Accepted: 13 March 2021 / Published online: 29 April 2021

(c) The Author(s) 2021

\begin{abstract}
Many laboratory experiments demonstrate how orb-web spiders change the architecture of their webs in response to prey, surroundings and wind loading. The overall shape of the web and a range of other web parameters are determined by frame and anchor threads. In the wild, unlike the lab, the anchor threads are attached to branches and leaves that are not stationary but move, which affects the thread tension field. Here we experimentally test the effect of a moving support structure on the construction behaviour and web-parameters of the garden cross spider Araneus diadematus. We found no significant differences in building behaviour between rigid and moving anchors in total time spent and total distance covered nor in the percentage of the total time spent and distance covered to build the three major web components: radials, auxiliary and capture spirals. Moreover, measured key parameters of web-geometry were equally unaffected. These results call for reevaluation of common understanding of spider webs as thread tensions are often considered to be a major factor guiding the spider during construction and web-operation.
\end{abstract}

Keywords Garden cross spider · Araneus diadematus · Silk tension · Web distortion · Web building · Web geometry

\section{Introduction}

Numerous studies have examined the intricate features of spider orb webs typically concluding that the features of orb webs are largely dictated by their function as prey traps (Fig. 1) (Burtscheidt et al. 2019; Dyson 2018; Krink and Vollrath 2000; Mortimer et al. 2014; Nyffeler 2009; Pasquet et al. 2013; Rhisiart and Vollrath 1994; Schneider and Vollrath 1998; Souza et al. 2007; Uetz et al. 1978; Vollrath et al. 1997; Wu et al. 2013; Zschokke 2011). For example, in vertical webs, the spiders build larger capture areas below the hub because they can run faster down than up, which encourages them to expand that area of their effective control (Rhisiart and Vollrath 1994; Watanabe 2000; Zschokke 2011). Whilst this functionality is easily tested, much more difficult to study are the effects of internal and environmental factors and the constraints they might impose

Communicated by: Matjaž Gregorič

Fritz Vollrath

fritz.vollrath@zoo.ox.ac.uk

1 Department of Zoology, University of Oxford, 11 Mansfield Road, Oxford OX1 3SZ, UK on webs (Anotaux et al. 2016; Dyson 2018; Hesselberg 2013; Mazzia et al. 2020; Pasquet et al. 2013; Schneider and Vollrath 1998; Tew and Hesselberg 2018, 2017; Vollrath et al. 1997; Wolff et al. 2020; Wu et al. 2013). For example, in windy conditions, spiders like the garden cross spider Araneus diadematus alter many web features (presumably in order to minimise wind damage) such as total web area, capture spiral area, web eccentricity, mesh space, capture spiral count, radial count, total radial length and total capture spiral length (Vollrath et al. 1997; Wu et al. 2013; Fig. 1). In another example, in constrained spaces, A. diadematus modifies many interconnecting key features of web architecture again showing the high degree of flexibility in the spider's web-construction algorithm (Krink and Vollrath 2000).

Whilst web building in spatially constrained and windy and environments demonstrates the spider's ability to adjust to rather static conditions, in nature the supporting structures often move relative to each other due branches swaying in the wind (Online Resource 1, Online Resource 2). Despite the common occurrence of this environmental disturbance, the effects of moving anchors on orb web building behaviour and orb web design stand unexamined. The potential effects of moving anchors are particularly interesting because spiders carefully manage silk tensions in their 


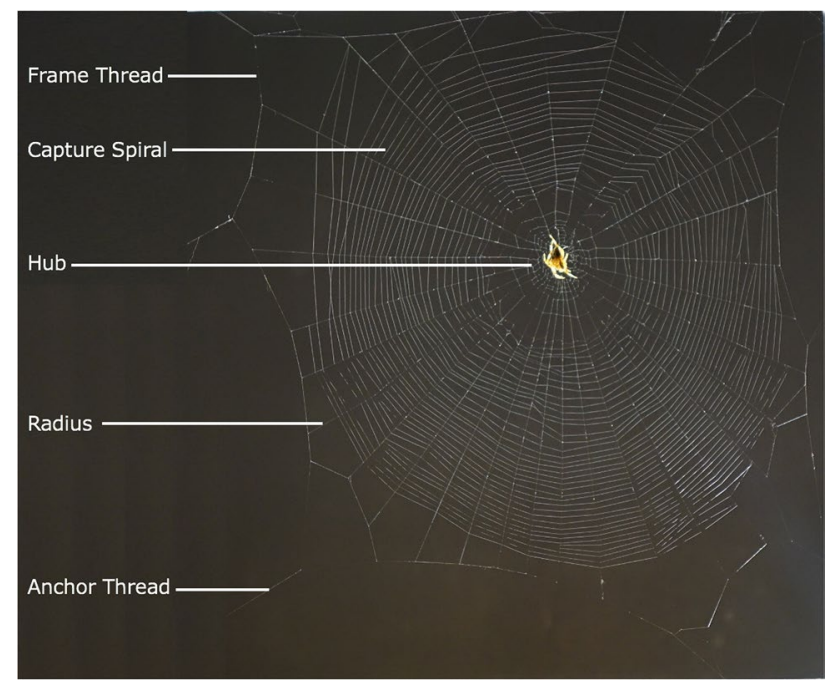

Fig. 1 Main features of an Araneus diadematus orb web

webs during construction (Eberhard 1981; Mortimer 2019; Watanabe 2000; Wirth and Barth 1992; Zschokke 1996) and independent anchor movements should cause continuous tensions changes in any established threads. Studying the effects of moving anchors may additionally demonstrate whether spiders dedicate more time consolidating structural components of webs in mechanically taxing (non-windy) environments, and if the strong association between wind and anchor movement in nature causes spiders to change their webs as they do in windy conditions.

Given these unknowns, the present study aimed to explore whether orb weavers alter their building behaviour and hence modify resulting web structures in the laboratory when anchors move continuously before, after and throughout the building period. We hypothesised that, when faced with moving anchors: (i) web construction would take longer, (ii) a greater percentage of the total construction time would be dedicated to structural components (radials, auxiliary spiral), (iii) the construction path would be more tortuous and (iv) web geometry might be adjusted comparable to builds in windy conditions.

\section{Materials and methods}

\section{Spider preparation}

Adult female Araneus diadematus were collected from several locations in Oxfordshire, England. Spiders were stored in our standard Perspex frames $(30 \mathrm{~cm} \times 30 \mathrm{~cm} \times 5 \mathrm{~cm})$ separated by greased Perspex sheets. Twice per week, they were watered with a spray gun and fed two Drosophila melanogaster. Spiders had to build three trial webs on consecutive days in standard frames to be able to be selected for experiments.

\section{Experimental method}

Spiders were transferred into individual flexible frames which are identical to standard frames but with bendable corners. Four flexible frames were placed in parallel in the frameshaking tool (henceforth 'shaker'). An electric motor moved 4 parallel mechanical arms, each of which could be attached to the bottom of a flexible frame with magnets. Under Rigid control conditions ' $R$ ', the flexible frame was detached from the moving mechanical arm and remained stationary. Under Moving treatment conditions ' $M$ ', the frame was attached to its arm and was repeatedly moving side to side (Fig. 2). To establish a workable frequency and configure the hardware, we cycled through circa 10 spiders (in addition to those used in the actual experiment) in a set of pilot trials, some of which were used for multiple trial settings. Ultimately, it was not possible to fully and consistently replicate the variability of anchor movements in nature (Online Resource 1), and during trials spiders refused to build webs altogether at frequencies $>0.05 \mathrm{~Hz}$. The results have been interpreted cautiously to reflect these experimental constraints.
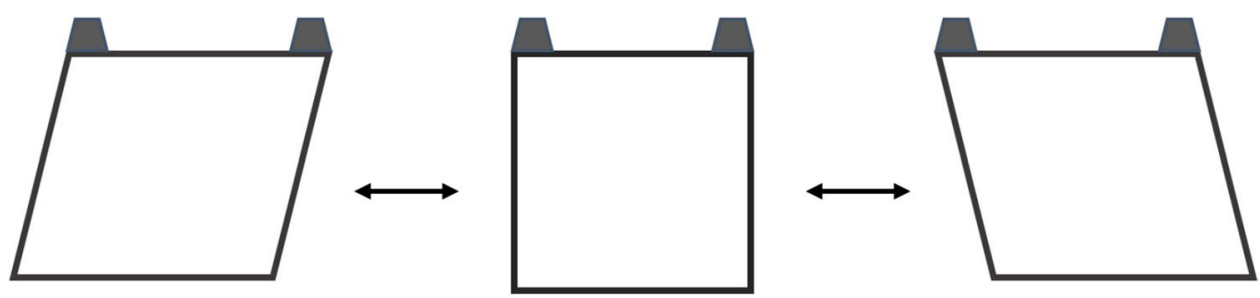

Fig. 2 Shaker induced movement of flexible frame. Dark blocks fixed flexible frames in shaker. When a frame was attached to a mechanical arm, the bottom panel of the frame shifted $\sim 10 \mathrm{~cm}$ left and right at $\sim 0.05 \mathrm{~Hz}$ whilst the top panel remained fixed in place. Higher moving frequencies were attempted but caused spiders to stop building webs altogether. All attached flexible frames moved in unison due to the parallel configuration. To control for motor-induced vibrations in the shaker, the front frame in the shaker was always empty and moving 
The experiments followed a 5-day $R R M R M$ regime. This $R R M R M$ regime is known as (multiple baseline) reversal design and is particularly suitable for small $\mathrm{N}$ research designs (Saudargas and Drummer 1996). We selected this design because we predicted that our challenging experiment would result in a small sample size. Put succinctly, the reversal design ensures that observed effects are unlikely to be caused by extraneous factors as it increases internal validity (Saudargas and Drummer 1996)and thus (partly) compensates for a small sample. On days where spiders did not build a web, the same run was repeated up to four consecutive days (e.g. $\left.R^{1} R^{2} R^{2} R^{2} R^{2} M^{3} R^{4} M^{5}\right)$ after which the spider was removed and the sequence was considered incomplete. Between runs, the webs were sprinkled with water and all radials were cut except for two radials leading North and South to the frame. Spiders were fed $1 D$. melanogaster per day of the experimental regime regardless of web building success and experimental conditions.

Building behaviour Web building was recorded with timelapses; one time-stamped photograph was obtained per $\sim 10 \mathrm{~s}$. With a custom tracking programme in Python, the coordinates of spiders and all frame corners were recorded for each photograph. Tracking began when spiders started web construction and terminated when the spider sat still at the hub. Raw tracks were corrected for shaker-induced movements in moving runs-because frame movements were greatest at the bottom, the correction was adjusted for the spider's latitudinal position in the frame. By scaling relative to the frames, the absolute distances between corrected coordinates were calculated.

From activity plots (Online Resource 3) and established activity signatures from (Zschokke and Vollrath 1995), we identified the photographs in which spiders started and completed construction of the radials, auxiliary spiral and capture spiral. This information was used to calculate four building behaviour variables; time differences between photographs were used to calculate the total web construction time and the percentage of time spent on each web component, and the absolute positional data were used to calculate the total distances covered during total web construction and the percentage of the distance covered per web component.

Web geometry The resulting webs were photographed (Panasonic LUMIX GH5 digital camera and Nikon AF NIKKOR $50 \mathrm{~mm}$ lens) and eight web measurements were obtained in ImageJ (Online Resource 4); measurements scaled relative to frames. These measurements were used to calculate the six wind-affected web features (Table 1). Whilst the total radial lengths and capture spiral length are also affected by wind (Vollrath et al. 1997), we did not include these features in the analysis as they are geometrically related to other included features; radial length is determined by web area and radial count, whilst capture spiral length is determined by capture spiral count, mesh space and capture spiral area.

\section{Data analysis}

The effects of moving anchors on web design features and building behaviour were examined with mixed models (Davies and Gray 2015) in which Spider ID was included as a random effect to adjust for pseudoreplication. The models thus examined whether anchor movement affected building behaviour and each web feature when adjusted for variation that naturally occurs between individuals.

Crucially, spiders may also use the experience of building one web under certain conditions when building the following web e.g. (Venner et al. 2000). Using boxplots, we visually assessed if there was an experience effect within the rigid data (days R1, R2, R3) or within the moving data (days M1, M2) for any of the variables of interest. The boxplots did not indicate a clear and significant experience effect (Online Resource 5-7).

The effects of moving anchors on capture spiral count and radial count data were assessed with generalised linear
Table 1 Analysed web design features

\begin{tabular}{ll}
\hline Features & Calculation (if applicable) \\
\hline $\begin{array}{l}\text { Total web area }\left(\mathrm{cm}^{2}\right) \\
\text { Capture spiral area }\left(\mathrm{cm}^{2}\right)\end{array}$ & $\begin{array}{l}\text { N/A (measured directly) } \\
\text { Eccentricity* }\end{array}$ \\
& $=\sqrt{\left(1-\frac{\text { Web width }}{\text { Web height }}\right)}^{2}$ \\
Mean capture spiral count** & $=\frac{\text { (North capture spiral count }+ \text { South capture spiral count) }}{2}$ \\
Mean mesh space** $(\mathrm{cm})$ & $=\frac{\text { (Width north capture spiral }+ \text { Width south capture spiral) }}{\text { (Count north capture spirals+ Count south capture spirals-2) }}$ \\
Radial count & N/A (measured directly) \\
\hline *Features calculated per the methods in Vollrath et al. (1997), **features calculated per the methods in Wu \\
et al. (2013). See Online Resource 4 for example photographs of how the measurements were taken from \\
webs. North, East, South and West indicate directions relative to the hub. We calculate web width=length \\
east radius + length west radius, and web height = length north radius + length south radius
\end{tabular}


mixed models (GLMMs); Poisson error distributions. All other dependent variables were continuous and analysed with linear mixed models (LMMs). Several continuous variables analysed with LMMs were log-transformed or inverse transformed to meet the assumption of normality which was verified with histograms, Q-Q plots and Shapiro Wilk tests (Online Resource 8).

Multiple LMMs and the radial count GLMM were overfitted (i.e. not optimally parsimonious (Hawkins 2004)) due to the inclusion of the random effect. However, because overfitting did not change model outputs at all, we opted to retain Spider ID in all models to accurately represent our experimental design throughout. Per the methods in (Thomas 2017), the capture spiral count and radial count GLMMs were also assessed for overdispersion (when variability in the data exceeds that predicted by the Poisson GLMM (Berk and MacDonald 2008)), and no significant overdispersion was detected (ratio $=0.69$, $p=0.82$ and ratio $=0.34, p=0.99$ respectively). The assumptions of all models were met.

Finally, as we examined four building behaviour variables, a Bonferroni correction was applied and $p \leq 0.013$ would indicate a significant effect. Likewise, because we examined six web design features, $p \leq 0.008$ would indicate a significant effect.

\section{Results}

\section{Sample size}

At a frame movement frequency of $0.05 \mathrm{~Hz}$, the experiment was attempted with 26 spiders, of which only five spiders
Fig. 3 Effect of moving anchors on web construction times. $\mathrm{SE}=$ standard error. Effect sizes for models with log-transformed and inverse-transformed dependent variables were calculated by back transformation of model outputs. $n_{\text {rigid }}=15$, $n_{\text {moving }}=9$. See Online Resource 5 for relevant boxplots indicating a lack of an experience effect

(a) Whole Web Total Construction Time (s) +/- 1SE

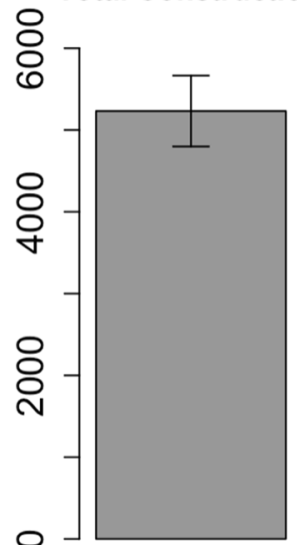

Rigid

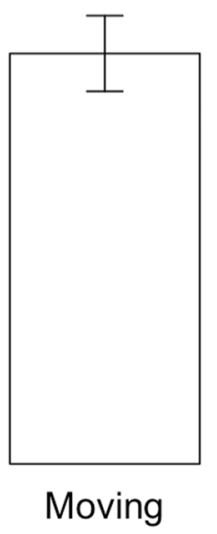

Frame State

(c) Auxiliary Spiral $\%$ of Total Time $+/-1$ SE

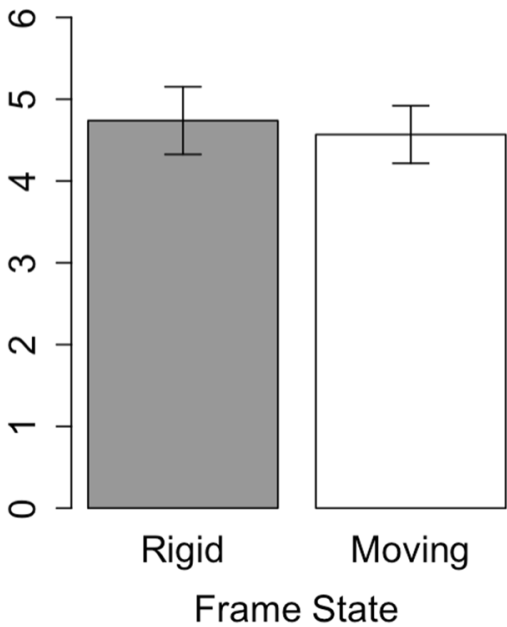

(b) Radials $\%$ of Total Time $+/-1$ SE

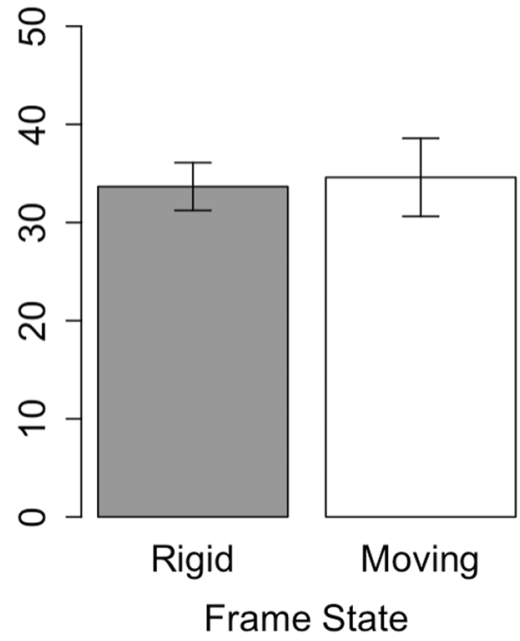

(d) Capture Spiral $\%$ of Total Time +/- 1SE

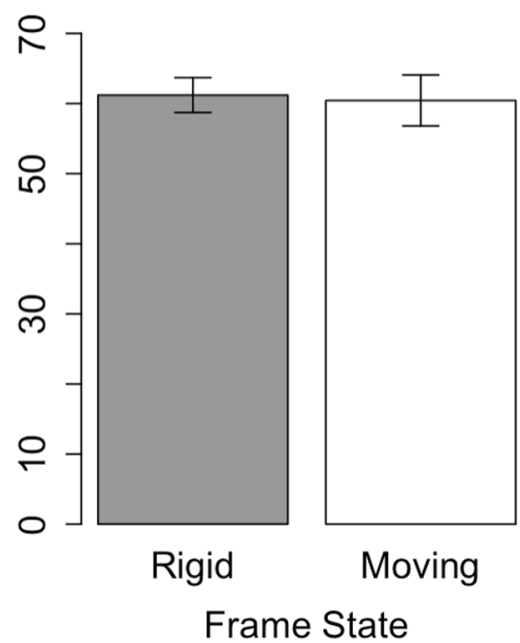


completed the full RRMRM experimental regime during the 11-month experimentation period. The small sample was thus not a consequence of spider availability, but instead, the experiment was limited by time and space availability in the shaker coupled with operational (filming) constraints.

The five successful spiders allowed us to obtain 25 timelapses $\left(n_{\text {rigid }}=15, n_{\text {moving }}=10\right)$, but 5 webs were broken upon removal from the shaker due to static and were not photographed for web measurements $\left(n_{\text {rigid }}=11\right.$, $n_{\text {moving }}=9$ ). On one occasion, a spider remained stationary for multiple extended periods partway through the build resulting in a total construction time of $15119 \mathrm{~s}$, more than twice as long as the next longest construction time by any spider (6805 s). As this behaviour was abnormal and created an extreme outlier in terms of web construction time, this run was excluded from the temporal web building analyses. This run was not excluded from the web design analyses and spatial web building analyses because the resulting web design and distances covered were not affected by this behaviour.

\section{Web building behaviour}

Anchor movement did not significantly affect the construction times ( $\mathrm{df}=18.2, t=-0.46, p=0.65)$ (Fig. 3a), or the percentage of the construction time spent on each web component (radials $\mathrm{df}=22.0, t=0.24, p=0.82$; auxiliary spiral $\mathrm{df}=18.0, t=0.43, p=0.67$; capture spiral $\mathrm{df}=18.5$, $t=-0.21, p=0.83$ ) (Fig. 3b-d).

Moving anchors also did not significantly affect the distances spiders covered $(\mathrm{df}=23.0, t=-0.52, p=0.61)$ (Fig. 4a), or the percentage of the total distance covered per web component (radials $\mathrm{df}=19.0, t=1.21, p=0.24$; auxiliary spiral $\mathrm{df}=19.0, t=0.82, p=0.42$ ) (Fig. $4 \mathrm{~b}-\mathrm{d}$ ).
Fig. 4 Effect of moving anchors on distances covered during web construction. $\mathrm{SE}=$ standard error. Effect sizes for models with log-transformed and inverse-transformed dependent variables were calculated by back transformation of model outputs. $n_{\text {rigid }}=15, n_{\text {moving }}=10$. See Online Resource 6 for relevant boxplots indicating a lack of an experience effect (a) Whole Web Total Distance $(\mathrm{cm})+/-1 \mathrm{SE}$

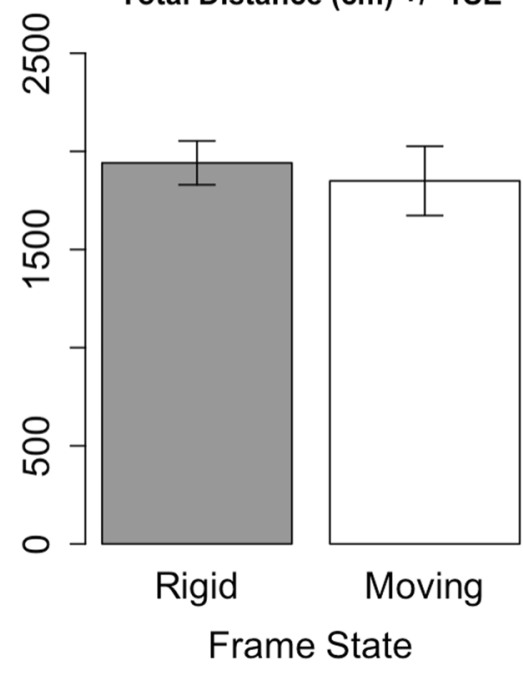

(c) Auxiliary Spiral $\%$ of Total Distance +/- 1SE

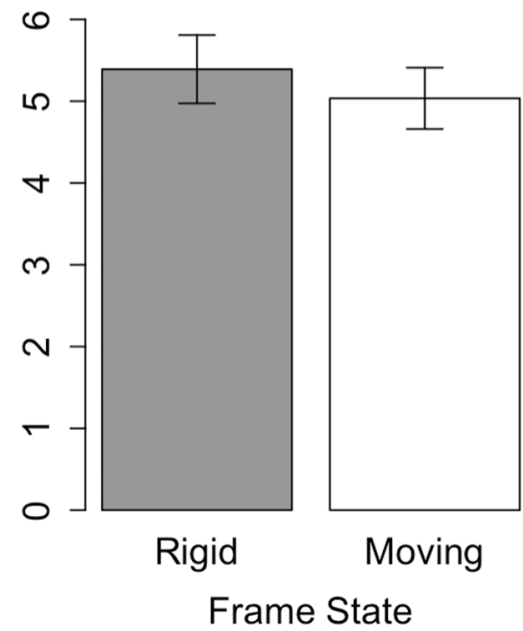

(b) Radials $\%$ of Total Distance +/- 1SE

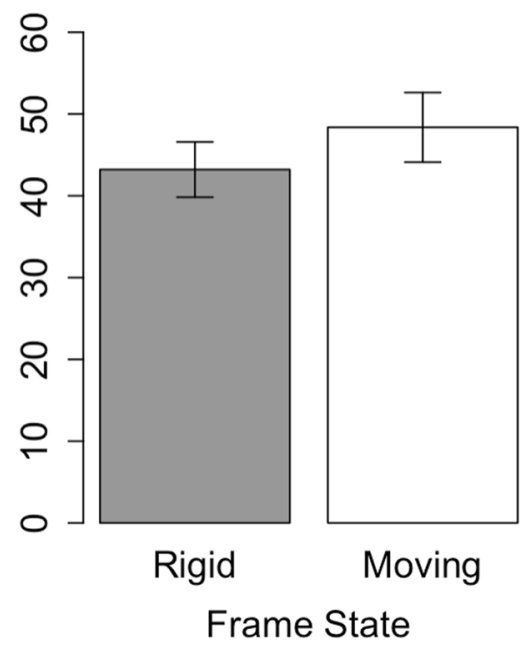

(d) Capture Spiral $\%$ of Total Distance +/- 1SE

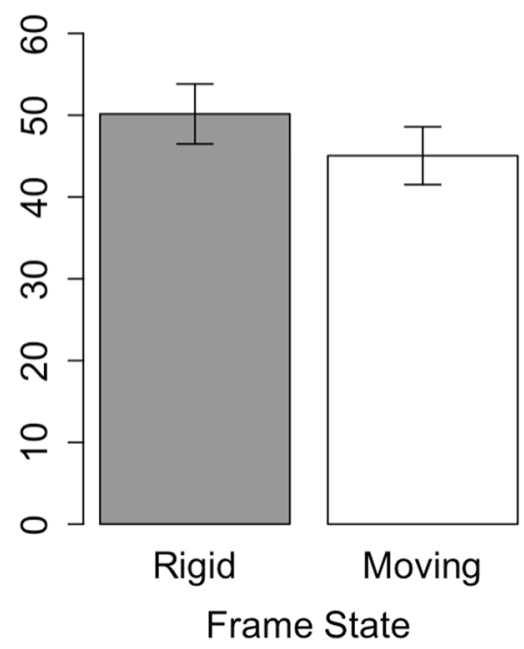




\section{Web geometry}

The area of whole webs and area of capture spirals were not significantly affected by anchor movement (web area $\mathrm{df}=14.4, t=-1.72, p=0.11$; capture spiral area $\mathrm{df}=14.4$, $t=-2.58, p=0.02$ ) (Fig. 5a,b). Likewise, the anchor movements did not significantly affect web eccentricity and mesh space (eccentricity df $=14.4, t=1.93, p=0.07$; mesh space $\mathrm{df}=14.1, t=0.03, p=0.98$ ) (Fig. $5 \mathrm{c}, \mathrm{d}$ ) or the number of capture spirals and radials in webs (capture spiral $z=-0.96$, $p=0.34$, radials $z=-1.50, p=0.13$ ) (Fig. 5e,f).

\section{Discussion}

Our treatment considerably sheared the web during construction by sinusoidal moving of the anchor points by approximately $40^{\circ}$ between the two maxima. Surprisingly, we found no significant effects of the shearing on both web building and a range of selected web features shown to be affected by blowing wind (Figs. 3, 4 and 5). This was unexpected because it is generally accepted that during web construction spiders regulate tensions (Eberhard 1981; Mortimer 2019; Watanabe 2000; Wirth and Barth 1992; Zschokke 1996) and our frame movements clearly affected the tensions in a cyclical fashion. Moreover, due to the common cooccurrence moving anchors and windy conditions in nature, one may have expected our artificial anchor movements to affect wind-sensitive web features, especially since our artificial anchor movements were slower than those observed in nature (Online Resource 1).

However, it must be noted that whilst the statistical tests did not detect a significant effect of anchor movement on web building behaviour and web features, the bar charts of several web features do indicate an influence of web movement (Fig. 5). A larger sample may have resulted in a
Fig. 5 Effect moving anchors on web geometry. SE = standard error. True effect sizes for d-f were calculated by back transformation of model outputs. $n_{\text {rigid }}=11, n_{\text {moving }}=9$. See Online Resource 7 for relevant boxplots indicating a lack of an experience effect (a) Web Area $\left(\mathrm{cm}^{\wedge} 2\right)+/-1 \mathrm{SE}$

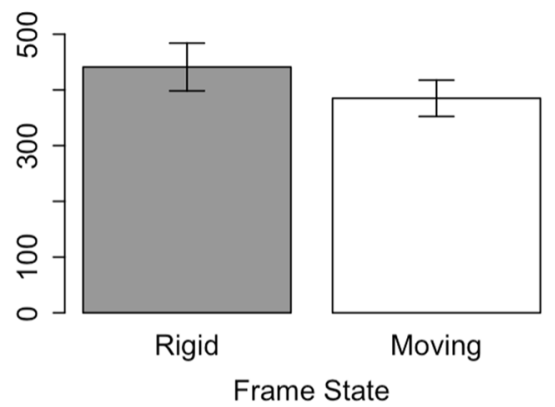

(c) Web Eccentricity +/- 1SE

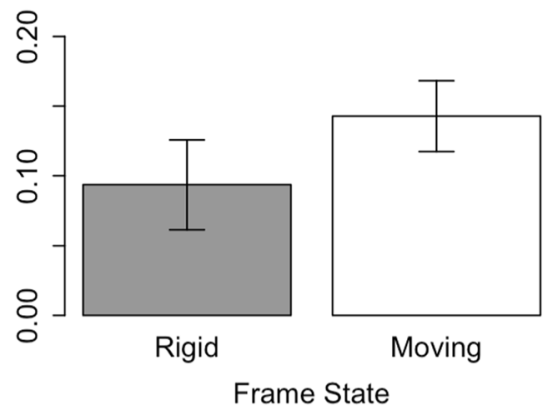

(e) No. Capture Spirals +/- 1SE

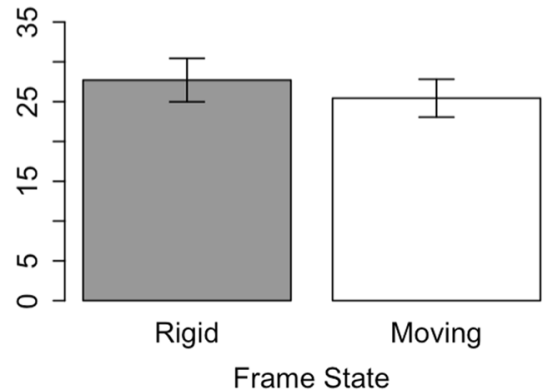

(b) Capture Spiral Area $\left(\mathrm{cm}^{\wedge} 2\right)+/-1 \mathrm{SE}$

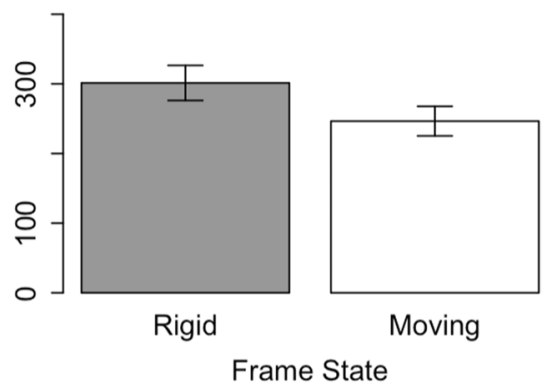

(d) Mesh Space $(\mathrm{cm})+/-1 \mathrm{SE}$

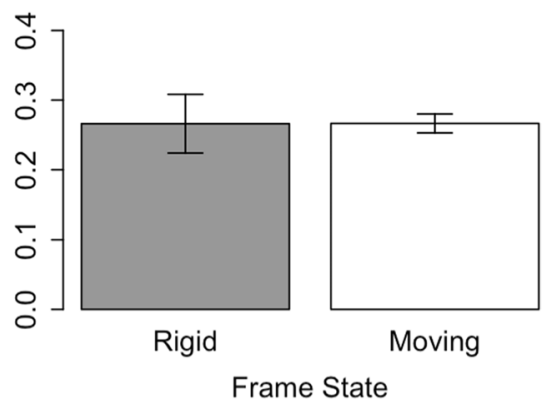

(f) No. Radials +/- 1SE

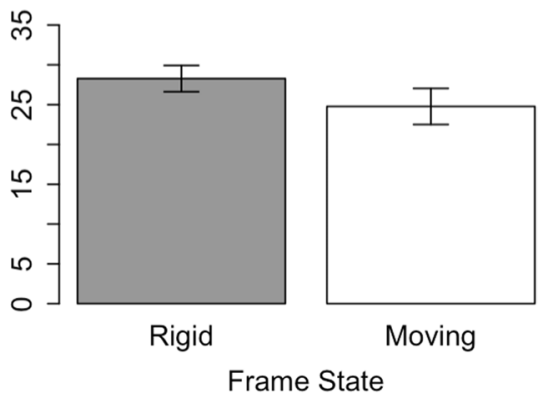


significant effect of anchor movement on specific web features. Furthermore, because our analysis only included those individuals which completed the entire RRMRM regime, we likely selected the most robust web builders in our captive population. Our exclusive use of these robust builders may have resulted in smaller effect sizes and the observed nonsignificant effects.

Our experiments nonetheless suggest that repetitive changes in thread tensions during web-construction may be balanced-out by the spider. There is some evidencefrom rotation and thread-cutting experiments-that orb spiders can average rapid modifications of sensory input (Reed 1969; Vollrath 1988). This mechanism allows the spider to use a robust 'rule of thumb' algorithm and avoid being confused by sensory input that might conflict with the expectations in the feed-back loop (Krink and Vollrath 2000). In a cybernetic control-theory analogy, this would amount to controlling a mismatch between measured values and set-points. Web-building is a dangerous process and rapid conclusion is of essence (Rypstra 1984; Vollrath 1992, 1980; Zschokke and Vollrath 1995). Final finetuning by adjusting the tensions once web-building is done is one way of finishing the trap (Mortimer et al. 2016; Watanabe 2000), although it appears that spiders can also locate prey using vibrations in webs that are distorted, and in which tensions are changed (Mulder et al. 2020).

We thus cautiously conclude that thread tensions are important but perhaps not as important as typically assumed at least whilst building the web. Notably, the visco-elastic properties of the silk will in itself contribute to the tension-landscape of a web both during and after building and it seems that our artificial anchor movements were not mechanically taxing on the structure of the web. However that might be, this study demonstrates, once again, that there is yet much more to study before we can say that we understand even the basics of spider webs and their construction process.

Supplementary Information The online version contains supplementary material available at https://doi.org/10.1007/s00114-021-01725-1.

Author contribution All authors shared in the conceptualisation, methodology, formal analysis, investigation and discussions with TM and FV also writing the manuscript.

Funding This work was funded by the Leverhulme Trust (Grant ID: RPG-2016-345). BM thanks the Department of Zoology University of Oxford and the Royal Society for funding.

Data availability Data available from the corresponding author upon reasonable request.

Code availability Statistical code and plots developed in RStudio. Code available from the corresponding author upon reasonable request.

\section{Declarations}

Ethics approval Not applicable, because this article solely studies nonvertebrate organisms (namely spiders) for which ethical approval is not required.

Consent to participate Not applicable, because no human subjects were studied.

Consent for publication Not applicable, because no human subjects were studied.

Competing interests The authors declare no competing interests.

Open Access This article is licensed under a Creative Commons Attribution 4.0 International License, which permits use, sharing, adaptation, distribution and reproduction in any medium or format, as long as you give appropriate credit to the original author(s) and the source, provide a link to the Creative Commons licence, and indicate if changes were made. The images or other third party material in this article are included in the article's Creative Commons licence, unless indicated otherwise in a credit line to the material. If material is not included in the article's Creative Commons licence and your intended use is not permitted by statutory regulation or exceeds the permitted use, you will need to obtain permission directly from the copyright holder. To view a copy of this licence, visit http://creativecommons.org/licenses/by/4.0/.

\section{References}

Anotaux M, Toscani C, Leborgne R, Chaline N, Pasquet A (2016) Time till death affects spider mobility and web-building behavior during web construction in an orb-web spider. Curr Zool 62:123-130. https://doi.org/10.1093/cz/zow001

Berk R, MacDonald JM (2008) Overdispersion and poisson regression. J Quant Criminol 24:269-284. https://doi.org/10.1007/ s10940-008-9048-4

Burtscheidt J, Claus M, Dempe S (2019) Detecting a prey in a spider orb web. SIAM J Appl Math 30:377-406. https://doi.org/10.1137/ 19M1262322

Davies GM, Gray A (2015) Don't let spurious accusations of pseudoreplication limit our ability to learn from natural experiments (and other messy kinds of ecological monitoring). Ecol Evol 5:5295-5304. https://doi.org/10.1002/ece3.1782

DysonGB (2018) Form and function of the orbweb. Contrib Kayak Stud. 259-318.https://doi.org/10.2307/j.ctv16zpd.14

Eberhard WG (1981) Construction behaviour and the distribution of tensions in orb webs. Bull Br ArachnolSoc 5:189-204

Hawkins DM (2004) The problem of overfitting. J Chem Inf Comput Sci 44:1-12. https://doi.org/10.1021/ci0342472

Hesselberg T (2013) Web-building flexibility differs in two spatially constrained orb spiders. J Insect Behav 26:283-303. https://doi. org/10.1007/s10905-012-9335-7

Krink T, Vollrath F (2000) Optimal area use in orb webs of the spider Araneus diadematus. Naturwissenschaften 87:90-93. https:// doi.org/10.1007/s001140050017

Mazzia C, Capowiez Y, Marliac G, Josselin D, Pasquet A (2020) Spinosad application in an apple orchard affects both the abundance of the spider Araneus diadematus and its web construction behaviour. Ecotoxicology 29:389-397. https://doi.org/10. 1007/s10646-020-02179-3

Mortimer B (2019) A spider's vibration landscape: adaptations to promote vibrational information transfer in orb webs. Integr Comp Biol 59:1636-1645. https://doi.org/10.1093/icb/icz043 
Mortimer B, Gordon SD, Holland C, Siviour CR, Vollrath F, Windmill JFC (2014) The speed of sound in silk: linking material performance to biological function. Adv Mater 26:5179-5183. https://doi.org/10.1002/adma.201401027

Mortimer B, Soler A, Siviour CR, Zaera R, Vollrath F (2016) Tuning the instrument: sonic properties in the spider's web. J R Soc Interface 13:1-10. https://doi.org/10.1098/rsif.2016.0341

Mulder T, Mortimer B, Vollrath F (2020) Functional flexibility in a spider's Orb Web. J Exp Biol 223, jeb.234070. https://doi.org/ $10.1242 /$ jeb. 234070

Nyffeler M (2009) Estimate of the daily catch of prey by the wasp spider Argiope bruennichi ( Scopoli ) in the field : original data and minireview. Contrib to Nat Hist 12:1007-1020

Pasquet A, Marchal J, Anotaux M, Leborgne R (2013) Imperfections in perfect architecture: the orb web of spiders. Eur J Entomol 110:493-500. https://doi.org/10.14411/eje.2013.065

Reed C (1969) Order of radius construction in the orb web. Bull Mus Narl Hist Nar 2:85-87

Rhisiart AA, Vollrath F (1994) Design features of the orb web of the spider, Araneus diadematus. Behav Ecol 5:280-287. https://doi. org/10.1093/beheco/5.3.280

Rypstra AL (1984) A relative measure of predation on web-spiders in temperate and tropical forests. Oikos 43:129. https://doi.org/10. $2307 / 3544758$

Saudargas RA, Drummer LC (1996) Single subject (small N) research designs and zoo research. Zoo Biol 15:173-181. https://doi.org/ 10.1002/(SICI)1098-2361(1996)15:2\%3c173::AID-ZOO7\%3e3.0. $\mathrm{CO} ; 2-8$

Schneider JM, Vollrath F (1998) The effect of prey type on the geometry of the capture web of Araneus diadematus. Naturwissenschaften 85:391-394. https://doi.org/10.1007/s001140050521

Souza ALT, Gonzaga MO, Vasconcellos-Neto J (2007) Prey capture behaviour in the social spider Anelosimus eximius (Araneae: Theridiidae): Responses to prey size and type. Ethology 113:856861. https://doi.org/10.1111/j.1439-0310.2007.01384.x

Tew N, Hesselberg T (2017) The effect of wind exposure on the web characteristics of a tetragnathid orb spider. J Insect Behav 30:273286. https://doi.org/10.1007/s10905-017-9618-0

Tew N, Hesselberg T (2018) Web asymmetry in the tetragnathid orb spider Metellina mengei (Blackwell, 1869) is determined by web inclination and web size. J Arachnol 46:370-372. https://doi.org/ 10.1636/JOA-S-17-065.1

Thomas R (2017) Data analysis with R statistical software: a guidebook for scientists, 2017 edn. Eco-explore
Uetz GW, Johnson AD, Schemske DW (1978) Web placement, web structure, and prey capture in orb-weaving spiders. Br Arachnol Soc 4:141-148

Venner S, Pasquet A, Leborgne R (2000) Web-building behaviour in the orb-weaving spider Zygiella $\mathrm{x}$-notata: influence of experience. AnimBehav 59:603-611. https://doi.org/10.1006/anbe.1999.1327

Vollrath F (1980) Male body size and fitness in the web-building spider. ZoolTierpsychol 78:61-78

Vollrath F (1988) Spiral orientation of Araneus diadematus orb webs built during vertical rotation. J Comp Physiol A 162:413-419. https://doi.org/10.1007/BF00606128

Vollrath F (1992) Analysis and interpretation of orb spider exploration and web-building behavior. Advances in the study of behavior. Elsevier Masson SAS. https://doi.org/10.1016/S0065-3454(08) 60144-8

Vollrath F, Downes M, Krackow S (1997) Design variability in web geometry of an orb-weaving spider. Physiol Behav 62:735-743. https://doi.org/10.1016/S0031-9384(97)00186-8

Watanabe T (2000) Web tuning of an orb-web spider, Octonoba sybotides, regulated prey-catching behaviour. Proc R Soc B Biol Sci 267:565-569. https://doi.org/10.1098/rspb.2000.1038

Wirth E, Barth FG (1992) Forces in the spider orb web. J Comp Physiol A 171:359-371. https://doi.org/10.1007/BF00223966

Wolff JO, Little D, Herberstein ME (2020) Limits of piriform silk adhesion-similar effects of substrate surface polarity on silk anchor performance in two spider species with disparate microhabitat use. Sci Nat 107:1-10. https://doi.org/10.1007/s00114-020-01687-w

Wu CC, Blamires SJ, Wu CL, Tso IM (2013) Wind induces variations in spider web geometry and sticky spiral droplet volume. J Exp Biol 216:3342-3349. https://doi.org/10.1242/jeb.083618

Zschokke S (1996) Early stages of orb web construction in Araneus diadematus Clerck. Rev Suisse Zool 2:709-720

Zschokke S (2011) Spiral and web asymmetry in the orb webs of Araneus diadematus (Araneae: Araneidae). J Arachnol 39:358-362. https://doi.org/10.1636/cb10-61.1

Zschokke S, Vollrath F (1995) Unfreezing the behaviour of two orb spiders. Physiol Behav 58:1167-1173. https://doi.org/10.1016/ 0031-9384(95)02062-4

Publisher's note Springer Nature remains neutral with regard to jurisdictional claims in published maps and institutional affiliations. 